\title{
Relationtionship of Authentic Leadership and Organisational Culture with Organisational Innovation in Pharmaceutical Industry
}

\author{
Moiz Mohammed, Rajeesh Viswanathan
}

\begin{abstract}
Purpose - The purpose of this paper is to investigate the relationship between authentic leadership and organizational culture which organizational innovation under VUCA business environment.Organizations must foster organizational innovation in the organizations for their sustainability(Chen, Zheng, Yang, \& Bai, 2016). Organizational Innovation is important for the continuity of organizations and organizations that do not innovate run a large risk to perish (Verlag, 2016).Organizational innovation is crucial for the survival of the organizations in the conditions and situations of volatility, uncertainty, complexity and ambiguity prevalent in the current global economy. Business is facing more challenges in this VUCA environment, especially in the pharma sector. This environment demands to work on innovative ways to strengthen the competitive advantage and to sustain the businesses. Due to this environment, there is a need for continuous and sustainable innovation for long-term survival of the organizations. This study intends to give insights into the organizational culture and authentic leadership which have an influence on the organizational innovation.

Design/methodology/approach - This study used positivist deductive approach. A deductive approach starts with well-defined theories and identified variables. A Survey was conducted with a structured questionnaire. The questionnaire was administered to the employees working in $R \& D$ project teams in the pharma sector. Multiple regression was used to test the hypothesized relationships.
\end{abstract}

Findings - Authentic leadership and Organizational culture showed significant relationship with the organizational innovation

Practical implications - Organizations should focus on creating the authentic leadership skills among the project team leaders to reap maximal organizational innovation and have an organizational culture topromoting organizational fosters organizational innovation. The study has practical implications for both the top management and individual employee working in theresearch-intensiveprojects in the organizations.

Originality/value - The findings contribute to theleadership, organizational culture, and innovation literature first by showing how authentic leadership influences organizational innovation and how the organizational culture play an important role in the organizational innovation in the pharma industry.

Index Terms: Authentic Leadership, Organisational Culture, Organisational Innovation.
Revised Manuscript Received on July 05, 2019.

Dr. Moiz Mohammed, Associate Professor, Nawab Shah Alam Khan College of Engineering and Technology, Hyderabad.

Dr. Rajeesh Viswanathan, Assistant Professor, Department of International Business, School of Management, Pondicherry University, Pondicherry

\section{INTRODUCTION}

Innovation is the cornerstone of human progress. Innovation is essential for the economic growth. Management of innovation is crucial for the organization sustainability and the economic growth of the nation. In the literature on innovation in different disciplines explored the concept of innovation from different vantage points. The innovation or the ability to innovate is influenced by a multitude of factors. This study focusses on the individual's perception of organizational level analysis of innovation and concentrates on both individual and organizational level factors like Authentic leadership, Innovation Culture which influence and foster organizational innovation in the Indian Pharmaceutical Companies.

Indian Pharmaceutical Companies play an essential role in providing the accessible and affordable medicine for the majority of Indian Population. The employees working in the R\&D divisions of these pharmaceutical companies play an indispensable role in developing country's knowledge competency which will make India compete globally and also providing affordable, innovative medicines for the Indian population. These pharmaceutical companies play a critical component of the Indian National Innovation system which contributes to the production of knowledge. The Government of India declared 2010-20 as the "Decade of Innovation." The government of India emphasized the importance of integration of science technology and innovation for the development of the society. "Science technology and innovation for the people" is the new paradigm of the Indian STI policy. In the global innovation index, India ranked 76th by holding a score of 33.70. STI policy and global innovation index clearly show that there is a need for innovation in India.

\section{THE NEED FOR THE PRESENT STUDY}

Placing India among in the galaxy of nations as a significant player in the field of science and technology by the year 2020 is the aim of the Indian STI policy. Scientists are part of the highly skilled human capital involved in Research and Development ( R \& D) activities which contribute to the economic development of a nation. $R \& D$ professionals in the pharmaceutical companies mainly scientists are engaged in high-risk work which involves uncertainty and failure. With the importance of R\&D in the pharmaceutical industry for the welfare of the society, the management of innovation plays an important role. It is essential to under that the individual and organizational factors which contribute to the innovation in these pharmaceutical companies which have an obligation to fulfill and help in nation building. The failures they face in their research will affect not only their concentration and performance but also their thought process and innovation which in turn may affect the economic growth of our country. In the light of the uncertainty and high volatility work environments,

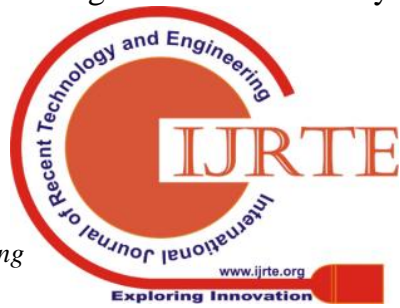


professionals must be provided constant support for innovation in the organization. An employee working in the intensive research settings may sometimes fail to see the idea and the product they worked on fail to succeed in the market. This employee who spends considerable time working on the innovative product may feel demotivated which may have a strong influence on the innovation process as a whole. The set back the employees face in R\&D settings are quite challenging require both organizational support and individual determination to keep going in tough conditions.

It is important to understand how policy interventions can be improved to support the individual employees in $\mathrm{R} \& \mathrm{D}$ intensive sectors more effectively. Organizational policies should be sensitive to need of the employees so that the R\&D can foster innovation and contribute to the economic development of the Nation and the improving the standard of living of the populations by providing innovative products and services in a sustainable manner.

The innovation policy in these organizations is more focused on the infrastructural support, and much importance is not given to the individual employees who work in these R\&D intensive sectors. The human resources policy must also incorporate policies which are oriented towards the individual and the organizational factors which foster innovation in these $\mathrm{R} \& \mathrm{D}$ intensive sectors. Indian pharmaceutical companies lag behind in the production of innovative technologies, our capability in technology assessment and forecasting as well as our knowledge of the international market are not entirely satisfactory. This combined with the no focus on the employees will affect the innovation culture and thereby changing the whole innovation process. On a general level, this study will have significant value for Indian pharmaceutical companies investing a lot of resources in the research and development to remain competitive in the globalized world. This research tries to give insights into organizational and individual factors which help these organizations to innovate. One of the important assumptions of this study was that the participants would feel comfortable and provide honest feedback regarding their experiences working in the research-intensive environment in the pharmaceutical company. The respondents in this study were all drawn from a select pharmaceutical company and may not represent all the employees working in research-intensive pharmaceutical companies.

\section{OBJECTIVES OF THE STUDY}

The research agenda for this research is established from a literature review on positive authentic leadership, an organizational innovation which influences organisational innovation, and how to foster a culture of innovation in research-intensive Indian pharmaceutical industry. The research gap identified is in determining factors that facilitate organisational innovation which in turns influence innovation and in developing interventions that can create conditions conducive to supporting innovation.

1. To study the influence of Authentic leadership on Organisational innovation in Indian research intensive R\&D pharmaceutical companies.

2. To study the influence of Organisational Culture on Organisational innovation in Indian research intensive R\&D pharmaceutical companies
Objective I: To study the influence of Authentic leadership on organisational Innovation in Indian research intensive R\&D pharmaceutical companies.

\section{$H_{0} 1$ : There is no relationship between Authentic leadership onOrganizationalinnovation in Indian research-intensive $R \& D$ pharmaceutical companies.}

Objective II: To study the influence of Organisational Culture on Organisational Innovation in Indian research intensive $R \& D$ pharmaceutical companies.

\section{$H_{0}$ 2: There is no relationship between Organizational Culture on Organizational innovation in Indian research-intensive $R \& D$ pharmaceutical companies.}

\section{LITERATUR REVIEW}

The literature review for this study has been done baby viewing the extent literature on the steady construct's authentic leadership organization culture and organizational innovation

Organisational culture assumes a discriminating part in organisations and impacts employees' observations, which affects on their practices. Organisational culture is seen as the whole of recognitions focused around the collaboration between the individual perception and organisational environment. Schneider and Hall (2010) exhibited organisational culture as a set of worldwide observations held by people about their environmental surroundings. The sets of discernments are fundamentally the after effect of cooperation's in the middle of individual and hierarchical qualities.

The connection between the measurements of organisational culture, view of backing for advancement and execution is directed by organisational slack and a solid association exists between the diverse measurements of organisational culture and view of backing for advancement (Antonia Ruiz-Moreno Väctor J. Garcia-Morales, Francisco Javier Llorens-Montes, 2008). There is a positive and solid relationship between assorted qualities administration and organisational culture measurements: strategies and systems, segregation, sexual orientation issues, uniformity in states of occupation, segregation and work value (Tjale, Tsedile Ethel, 2005). Zhang, Jianwei , Liu, Yuxin (2010) explored that organisational culture had significant main effects on human resources management effectiveness such as turnover intention, job satisfaction and work efficacy; organisational culture also had significant main effects on organisation effectiveness like staff members' organisation commitment and collective identity.

Georgopovles (1960) defines, "Organisational culture as a normative organization of attitude and behavioural standards which provide a basis for interpreting the situations and act as a source of pressure for directing activities". Organisational culture is the perception where people have about an organisation and global expression of what it is Benjamin Schneider and Rover, A. Snyder (1975). The belief and attitudes held by individuals about the organisation is psychological culture and the enduring quality of an organisation about culture is influencing their behaviour and experiences by employees Glick (1985).

Ekvall (1990) the conglomerate of attitudes, behaviours and feelings are the characteristics of an organisation but even with the disagreements most of them seem organisational culture as a stable thing to attitudes and which affects people's behaviour.

Koys and DeCotis (1991) states psychological culture as a description and not as evaluation of experience. It defines "an experimental-based,

multidimensional, and enduring perceptional phenomenon, which 
is widely shared by the members of a given organisational unit."

Schneider (1975) defines culture as perception which helps to make sense, know and behave and it also states that culture is subjective and its an individual attribute. Similarly "organisational culture a psychological meaningful cognitive representations of the situations James and Jones (1974) and attribute of the individual, which is learned, historical and resistant to change James and Sell, 1981

Friedlander and Margulics (1969) in their study determined the relationship between organisational and job satisfaction and it also links with various attributes. Stren (1970) explored the association between a personal needs and perception of culture using Murray's 'need press' theory framework for both personality measure and culture measure. Available attitudes of individuals, substantial knowledge are important for understanding organisational behaviour Hackman (1976)

Pareek (1989) proposed a framework on motivation which is relevant to organisational culture and is also called "motivational Culture" and six motives and six motives like experience, influence, achievement, affiliation, extension, control and dependency was given by him and he further contended that twelve dimensions of organisational culture relate specifically to motivation: orientation, interpersonal relationships, supervision, management, communication, decision making, trust, management of rewards, risk taking, and innovation and change.

Victoria Bellou, Andreas I. Andronikidis (2009) demonstrated that proficiency, reflexivity, advancement and adaptability, supervisory backing and quality were among the most conspicuous qualities influenced by organisational culture, while outward center and weight to create were slightest influenced. Also, the main contrasts uncovered in the middle of managerial and non-managerial employees were in the regions of contribution and effectiveness.

Forehand, G.a., \& Glimer, B.h. (2009) plot three gimmicks of organisational culture: firstly, it shifts among distinctive organisational; besides, it is tireless; finally, it can influence the conduct of organisational parts. Filipe Jorge Coelho, Mårio Gomes Augusto, Arnaldo Fernandes Coelho, Paträcia Moura Sa (2010) created a structural mathematical statements model also experimentally tried, demonstrating that impression of client, moral, and innovation cultures apply a circuitous impact on the appropriation of customer oriented practices by cutting edge employees.

Honest Friedlander and Newton Margulies (2004) investigated the various effect of organisational culture parts and individual employment values upon laborer's fulfillments and the mixes of distinctive culture parts which expand work fulfillments are directed by the work values held by the employee.

Schneider, White, and Paul (1998) inspected how administration arranged practices by employees can advance reporting of positive client administration experiences.

\section{METHODOLOGY}

This study adopts positivist deductive approach it, starts with explicit variables that are derived from theory and based on these variables, testable hypothesis is framed and is tested. This study will use a quantitative approach since all the variables in the survey are quantifiable. A structured questionnaire is used for collection of the data for the study. The present study is a descriptive and analytical aiming to bring out the relationship between Authentic leadership, Innovation culture, organizational innovation in Indian Pharmaceutical companies in India. The Scope of the survey includes employees working in the Indian pharmaceutical company.

\section{Population and Sample}

Given the scope and objectives of current research, the sample for the current study consist of an employee's working in the research and development projects in the Indian pharmaceutical companies A self-reported well-structured questionnaire is used to measure authentic leadership innovation culture, organizationalinnovation.

\section{RESEARCH VARIABLES AND MEASURE}

Adopting an existing instrument has an advantage of easy and inexpensive, and the questionnaire is pretested in at least one culture. Due to the advantage of the use of existing surveys, this study has used the existing questionnaire based on a thorough literature review. Authentic leadership, Innovation culture, are used as an independent variable in this present study. Organizationalinnovation is used as dependent variables. A thorough literature analysis was carried out to formulate a questionnaire for measuring the study variables Authentic leadership , organisatonal culture and organisational innovation. A structured questionnaire is used to collect the data. The respondents for the study are the employees working in the $\mathrm{R} \& \mathrm{D}$ divisions on Indian pharamecutical companies.

\section{DATA ANALYSIS TECHNIQUE}

The data analysis was done using SPSS 20Multiple regression will be the multiple regression was used for hypotheses testing.

\section{RESULTS}

Objective I: To study the influence of Authentic leadership on Organinsational Innovation in Indian research intensive R\&D pharmaceutical companies.

\section{$H_{0} 1$ : There is no relationship between Authentic leadership and Organizational innovation in Indian research-intensive $R \& D$ pharmaceutical companies.}

Multiple regression was used to test the Hypothesis among the study constructs.

\section{Model Summary}

\begin{tabular}{|l|l|l|l|l|}
\hline Model & $\mathrm{R}$ & $\begin{array}{l}\mathrm{R} \\
\text { Square }\end{array}$ & $\begin{array}{l}\text { Adjusted R } \\
\text { Square }\end{array}$ & $\begin{array}{l}\text { Std. The } \\
\text { error of the } \\
\text { Estimate }\end{array}$ \\
\hline 1 & $.798^{\mathrm{a}}$ & .637 & .632 & .59658 \\
\hline
\end{tabular}

a. Predictors: (Constant), Organizational Culture, Authentic leadership

\section{b. Dependent Variable: Organizational Innovation}

\section{Interpretation:}

$\mathrm{R}$ is the correlation; its value is 0.798 and the $\mathrm{R}$-square value if the degree of determination, its value is .637. The degree of determination shows the extent to which Authentic leadership and organizational culture influence organizational innovation. Here the organizational innovation is determined to the extent of $63 \%$ by Authentic leadership and Organizational culture. 


\begin{tabular}{|c|c|c|c|c|c|}
\hline \multicolumn{6}{|c|}{ ANOVA } \\
\hline Model & $\begin{array}{l}\text { Sum of } \\
\text { Squares }\end{array}$ & df & $\begin{array}{l}\text { Mean } \\
\text { Square }\end{array}$ & $\mathrm{F}$ & Sig. \\
\hline Regression & 91.708 & 2 & 45.854 & 128.836 & $.000^{\mathrm{b}}$ \\
\hline 1 Residual & 52.319 & 147 & .356 & & \\
\hline Total & 144.027 & 149 & & & \\
\hline
\end{tabular}

b. Predictors: (Constant), Organizational Culture,Authentic leadership

Anova Table shows that the significant value is less than .000 , which means that the dependent variable that is Organizational innovation is significantly predicted by the independent variables namely Organizational culture and Authentic leadership at $99 \%$ confidence level.

a. Dependent Variable: Organizational Innovation

Coefficients

\begin{tabular}{|c|c|c|c|c|c|}
\hline \multirow[t]{2}{*}{ Model } & \multicolumn{2}{|c|}{$\begin{array}{c}\text { Unstandardized } \\
\text { Coefficients } \\
\end{array}$} & $\begin{array}{l}\text { Standardized } \\
\text { Coefficients }\end{array}$ & $\mathrm{t}$ & Sig. \\
\hline & $\mathrm{B}$ & Std. Error & Beta & & \\
\hline (Constant) & .275 & .211 & & 1.305 & .194 \\
\hline 1 Authentic leadership & .049 & .105 & .041 & .468 & .000 \\
\hline Organizational Culture & .877 & .100 & .764 & 8.771 & .000 \\
\hline
\end{tabular}

a. Dependent Variable: Organizational Innovation

\section{Organisational Innovation $=.275+$ \\ .049 (Authentic leadership) + .877 (Organisational culture) $+\varepsilon$}

According to the model the hypothesis $H_{0} l$ is rejected, and it shows that there is a significant relationship between the Authentic leadership and Organizationalinnovation in Indian research-intensive $R \& D$ pharmaceutical companies.

Objective II: To study the influence of Organisational culture on Organisational Innovation in Indian research intensive R\&D pharmaceutical companies.

$H_{0}$ 2: There is no relationship between Organizational culture andOrganizational innovation in Indian research-intensive $R \& D$ pharmaceutical companies.

According to the model the hypothesis $H_{0} 2$ is rejected, and it shows that there is a significant relationship between the Organizational culture and Organizational innovation in Indian research-intensive $R \& D$ pharmaceutical companies.

\section{CONCLUSION}

In the competitive world, the success and survival of the organizations and nations are based on the capability to be innovative on a sustainable basis; the organizations are dependent on the human capital available in the organization. For countries to be prosperous in the globalized economy, it must be a leader in innovation. Innovation adds value to the business, allowing adaptation to new challenges and promising sustainability in the face of changing market demands and growing environmental and economic pressures. Innovation is thought of as the successful application of new ideas or knowledge, and it is essential for the organizations to understand how to leverage the creative potential of the employees working in the organization.

Innovation in these pharmaceutical companies is crucial for India to cater to the need of the society. It is essential to identify the issues which foster organisational innovation in these R\&D intensive organizations. Effective and efficient of human resources is critical for the success of these organizations. The organizations must select employees who display a positive authentic leadership. The organizations should develop programs to enhance the authentic leadership among the employees who are working in the research-intensive $R \& D$ divisions. Providing frequent motivational training program can develop a positive approach among employees. The organization must provide a conducive innovation culture to promote organizational innovation. The organizations must provide conducive innovation culture to foster innovation.

\section{LIMITATIONS AND DIRECTIONS OF FUTURE RESEARCH}

This research work also has its own limitations that can be addressed in future research. The first limitation of this research work is that the data was collected by self-report measurement instruments. Self-report data can be prone to response biases from the respondent. Future research can focus on the individual dimensions of the study construct to get deeper insights.

\section{REFERENCES}

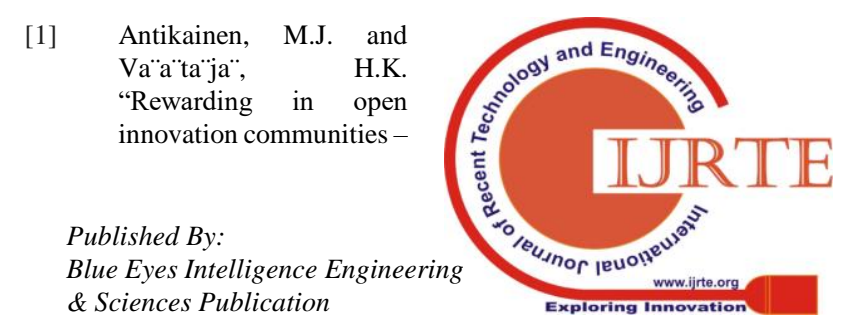


how to motivate members", International Journal of entrepreneurship \& Innovation Management, 11 (4):440-456 (2010).

[2] Antonia Ruiz-Moreno, Victor J. GarcÄa-Morales, Francisco Javier LlorensMontes., The moderating effect of organisational slack on the relation between perceptions of support for innovation and organisational culture. Personnel Review. 37(5): 509-525 (2008).

[3] Bulent, A. and Adrian, C. "The role of organizational culture on effectiveness", Ekonomie a Management, 12(3): 33-49 (2009).

[4] Burton, R., Lauridsen, J. and Obel, B., "Return on assets loss from situational and contingency misfits", Management Science, 48(11) (2002)

[5] Carmeli, A. "The relationship between emotional intelligence and work attitudes, behavior and outcomes: an examination among senior managers", Journal of Managerial Psychology, 18(8): 788-813 (2003)

[6] Choenarom, C., Williams, R.A. and Hagerty, B.M. "The role of sense of belonging and social support on stress and depression in individuals with depression", Archives of Psychiatric Nursing, 19(1):18-29 (2005).

[7] Choenarom, C., Williams, R.A. and Hagerty, B.M. "The role of sense of belonging and social support on stress and depression in individuals with depression", Archives of Psychiatric Nursing, 19(1): 18-29 (2005).

[8] Clark, M. "The relationship between employees' perceptions of organisational culture and customer retention rates in a major UK retail bank", Journal of Strategic Marketing , 10(2): 93-113 (2002).

[9] Clegg, S., "Globalizing the intelligent organization: learning organizations, smart workers, (not so) clever countries and the sociological imagination", Management Learning, 30(3):259-280 (1999)

[10] Davidson, Michael Cameron Gordon., Organisational culture and its influence upon performance: A study of Australian hotels in South East Queensland Griffith University (2000).

[11] Ekvall, G. and Ryhammar, L., "Leadership style, social culture and organizational outcomes: a study of a Swedish University College", Creativity and Innovation Management, 7(3) (1998).

[12] Ferrary, M., "Specialized organizations and ambidextrous clusters in the open innovation paradigm", European Management Journal, 29(3): 181-192 (2011).

[13] Frank Friedlander and Newton Margulies., Multiple Impacts of Organisational Culture and Individual Value Systems Upon Job Satisfaction Human Resource Management, 43(1) (2004) . Article first published online: 19 APR 2004.

[14] Galbraith, J., "Organization design: an information processing view”, Interfaces, 4(3) (1974)

[15] Herzberg, F., Mausner, B. and Snyderman, B.B., The Motivation to Work, Wiley, New York, NY (1959).

[16] James, L.R. and Jones, A.P., "Perceived job characteristics and job satisfaction: an examination of reciprocal causation" (1980).

[17] James, L.R. and Tetrick, L.E., "Confirmatory analytic tests of three causal models relating job perceptions to job satisfaction", Journal of Applied Psychology , 71( 1):. 77-82 (1986).

[18] Jung, D., Chow, C. and Wu, A., "The role of transformational leadership in enhancing organizational innovation: hypothesis and some preliminary findings", The Leadership Quarterly, 14, 525-44 (2003).

[19] Koene, B.A.S., Vogelaar, A.L.W. and Soeters, J.L., "Leadership effects on organizational culture and financial performance: local leadership effect in chain organizations", The Leadership Quarterly, 13(3): 193-215 (2002).

[20] Koskinen, K.U., Pihlanto, P. and Vanharanta, H., "Tacit knowledge acquisition and sharing in a project work context", International Journal of Project Management, 21( 4): 281-290 (2003).

[21] Lawler, E.E., Hall, D.T. and Oldham, G.R., "Organizational culture: relationship to organizational structure, process and performance", Organizational Behavior and Performance, 11, 139-55 (1974).

[22] Lie, A., "Coordination processes and outcomes in the public service: the challenge of inter-organizational food safety coordination in Norway", Public Administration, 89(2): 401-417 (2011).

[23] McAllister, D. (1995), "Affect and cognition-based trust as foundation for interpersonal cooperation in organizations",
Academy of Management Journal, 38(1): 24-59 (Special Forum on Intra and Inter organizational Cooperation).

[24] McKenna, S., "Storytelling and 'real' management competence", Journal of Workplace Learning, 11(3): 95-104 (1999).

[25] Mumford, M.D., Scott, G.M., Gaddis, B. and Strange, J.M. "Leading creative people: orchestrating expertise and relationships", The Leadership Quarterly, 13, 705-50 (2002).

[26] Pareek, U., Motivation and Organizational Culture, Division of Research, Harvard Business School, Boston, MA (1989).

[27] Pareek, U., Motivation and Organizational Culture, Division of Research, Harvard Business School, Boston, MA (1989).

[28] Patterson, K.A., Leadership Practices , Regent University Law School Admissions, Virginia Beach, VA . (2005).

[29] Patterson,M.G.,West,M.A., Schackleton, V.J., Dawson, J.F., Lawthom, R., Maitlis, S., Robinson, D.L. and Wallsace, A.M., "Validating the organizational culture measure: links to managerial practices, productivity and innovation", Journal of Organizational Behavior, 26(3):79-408 (2005).

[30] Personnel Psychology, Vol. 33 No. 1, pp. 97-135.

[31] Schneider, B. J., \& Bowen, D., Employee and customer perceptions of service in banks: replication and extension. Journal of Applied Psychology, 70, 423-433 (1985).

[32] Schneider, Benjamin; Hall, Douglas T., toward specifying the concept of work culture: A study of Roman Catholic diocesan priests. Journal of Applied Psychology, 56(6):447-455 (2010).

[33] Sourati, P. and Alipour, H., "Identifying the stress reducer factors in workplaces of public organizations of Astara city", Australian Journal of Basic and Applied Sciences, 5(7):. 321-324 (2011).

[34] Tanford, S., Raab, C. and Kim, Y.S., "The influence of reward program membership and commitment on hotel loyalty", Journal of Hospitality \& Tourism Research, 35(3):279-307 (2011).

[35] Tjale, Tsedile Ethel., The relationship between organisational culture and diversity management. Proquest Dissertations and Theses, 2005.

[36] Zhang Zhen, Ma Li, Ma Wenjing., The relationship between organisational culture and employee involvement: an empirical study on companies in Chinese context Journal of Chinese Psychology Acta Psychological Sinica (2003). 